tated for this servica, and, of course, was dismissed from his office.

A few of the patients have complained of aching about the cjebrows; but the greater part sustain no pain or inconvenience, except that arising from the blindness at night. They appear to see tolerably well during the day, but at sunset the sight becomes dim, and as the darkness increases, the dimness of sight increases, until they become totally blind. On a care ful examination, the only deviation from the normal character of the eye observable is a dilatation of the pupil, indicating diminished sensibility of the retina-the probable cause of the blindness in a dim light. The sight docs not sustain any permanent injury; as, after midsummer, in those cases which occur in the spring, it is as good as it was before the attack.

The parties aftected by it do not take so much notice of it now as they did when it first occurred, for they find by experience that it ceases at midsummer, and that medicine has but little influence upon it. The popular remedy is the effluvium from fried bullock's liver, but it appears to have but little if any good effect. Five grains of bluc pill taken at becl-time relieves the brow-ache, and seems-at least, in the opinion of the sufferers-to mitigate the affection, so as to have acquired for the medicine the name of " night-blind pills". Patient endurance, fortified with the confiderice that the affection will cease at midsummer, and the careful avoidance of being from home ufter sunset, is, however, on the whole the best course for the sufferer to pursue.

\section{LABOUR, WITH PERFECT OBLITERATION OF THE OS UTERI.}

By R. G. Mayse, M.D., Surgeon, Leeds. [Continued from page 552.$]$

I sTATED that I had neither heard nor read of a strictly analogous case, and now offer the grounds of this qualified statement.

The late Dr. Wm. Campbell of Eliuburgh, in his obstetrical work, relates two cases of very close contraction of the os thus : "Both were first pregnancies: in the first, uterine action continued about twelve hours before the os uteri could be distinguished, when it felt like a minute cicatrix." . . . "The second had regular pains for two nights and a day before the os uteri could be perceived, and she suffered so severely as to require three persons to keep her in bed. Buth patients were largely bled, gave birth to living children, and had a good recovery."

Cburchill had “ $n$ case in which the os uteri was not observable until after forty hours of labour, and then it was felt about the size of a small crowquill. Notwithstanding the delay and obstruction, however, the paticnt was delivered naturally of a living child."

Rigby says: "We may suspect the protraction of labour arises from agglutinated os uteri when at an early period of it we can discorer no restige of the opening in the globular mass formed by the inferior segment of the uterus, which is forced down into the pelvis, or at auy rate when we can only detect a small fold or fossa, or merely a concavity, at the lottom of which is a slight indentation, and which is usually a considerable distance from the median line of the pelvis. The pains come on regularly and powerfully; the lower segment of the uterus is pushed deeper into the eavity of the pelvis, even to its outlet, and becomes so tense as to threaten rupture; at the same time, it becomes so thin that a practitioner who sees such a case for the first time would be induced to suppose the head was presenting, merely covered by the membranes. After a time, by the increasing severity of the pains, the os uteri at length opens, or it becomes necessury that this should be effected by art; when once this is attained, the os uteri goes on to dilate, and the labour proceeds naturally, unless the patient is too much exhausted by the severity of her labour."

Burns (Midwifcry, ed. ix, p. 4(i0) states: "The os uteri may be naturally very small. In some instances, it has with difficulty ailmitted a sewing meerle; and in somo instances I found it impervious, hard, circular, and with difficulty discovered, but it gradually dilated."*

These cases, real and hypothetical, refer to first pregnancies,

- "In a case probably of thls lind, hom Guy's IIospital heports, no os uteri could be felt. An incision w's made into the tuunour formed by tho uterus in the vagina, and the contractions seem to have lacerated this farther. Great exhaustion followed the laceration and birth of he child, with rapid pulse; but the patient recovered." (Lanct, June 103\%, p. 39\%.) and to patent, though extremely constricted os, in one instance indistinguishable till after twelve hours action of the uterus, when it felt "like a minute cicatrix"; in another, imperceptible till after "regular pains for twn nights and a day"; in a third, not discoverable till " after forty hours of labour"; in a fourth, similarly hidden till after protracted labour. They therefore do not present the strict analogy to that forming the subject of this paper, which has been referred to, MIrs. W. having had several children, and there being no patency of the os whatever.

Burns continues: "It is also possible for the os uteri to be closed in consequence of inflammation, so that it has been necessary to make an urtificial opening." + This is the only mention of obliterated os uteri the result of inflammation, which, in my limited resources of reference, I have been able to meet with. In conjunction with it, I take the liberty of here repeating, from the passage in the Dictionnaire le Medecine quotel by Mr. Hatton, the only sentence to my purpose :"But it is also demonstrated by fucts of anatomical pathology, that the orifice becomes completely obliterated in consequence of inflammation of the mucous membrane which invests it." Mr. Hatton's case appears not to have been of this character at all, but similar to those previously cited; for although, in it, the constriction or contraction was so great that "no os uteri could be detected," there had bcen no disease of the womb, so far as ascertainable; and the impregnation indisputably implies some degree of patency, however minute. Then, it was a first pregnancy, and the patient had menstruated regularly from the age of sixteen (whether this regularity has regard to time, or quantity, or both, is not stated): and there was " a slight degree of puckering, or rather roughiness," concluded to be the site of the (assumed) imperforate os uteri.

The two extracts in the preceding paragraph, from Burns and the Dictionnaire de Médecine, are well illustrated by the casc renorted by me, some of the antecedents of which $I$ will now give. Mrs. W. had long been severcly aftlicted by a con. dition of the womb which, though its real character is still matter of dispute, is well understood by ulceration of the mouth and neck, accompanied by excessive discharge, much pain and exhaustion. She came under my care towards the close of 1855 , in a very broken-down condition; life seemed burdensome, and she was scarcely able to move about, having becn an invalid from the same cause, in greater or less severity, for some years before, during which she had not been pregnant, and had undergone medical treatment without relief. A few weeks attention, on the principles so ably laid down by Dr. Bennet, very much improved her state; and, by perseverance in the same course for a further period, she ccased to come to me, bcing quite restored to health, and in the enjoyment of comfort and strength, which she had long been deprived of. I heard no more of her till she called to engage me to attend at her confinement.

With reference to my inquiries at the bedside, alrealy referred to, as to any seusation of uneasiness in the uterine region after she became awnr quently drew from her the following facts :- That, in her fifth month, as she thought, she accompanied her husbaud on an excursion trip by railway to DIanchester; that, as is usual on such "pleasure" jaunts, the progress, what with stoppages and delays, was made as tedious as possible, causing her considerable uneasiness then and during her fatiguing wallis through the streets; that they left Manchester about 10 o'clock at night, and arrived again at Leeds between 4 and 5 next morning. This long confinement to a cramped position greatly increased the uneasiness in the luwer part of the body, so that she had much pair and diffieulty in reaching her home, which is about three quarters of a mile from the railway station. Her sufferings in this way continued till within six weeks of her delivery, when they altogether ceased; but she had not applied for help any where, under the idea that, though un. known in her past experience, they depended upon her pregnancy. I sulmit that there is here a satisfactory explanation of a case which, so far as I have been able to discover, is singular as to the perfect obliteration of the os, not only after impreguation, but after several natural full-timed births.

+ " Vide Case by Campardon, in Recusil Period. tom. xii, p. 22\%. Muscat gives a case where, in consenuence of injury by the furceps, the os uteri was so small that it would not admit a probe. $\lambda$ number of incisions were made round it, after which it dilated. In the next preguancy, slighter incisions sufnced; and in the last, none were reifuirel. dubertin perfurmed in case of this kind the Casarcan operation. In a subsequent precmancy, in the seventh month, the cicatrix was runtured, and by very little enlarremen a child was successtully extracted. In a case by ciautier, the os uteri was a child wis suceessfilly extrneten. Th a case by cautier, ho os uteri was were retained, and required a perfuration for their eracuation." 
A fow worls as to the treatment. In mentioning this case to one or two professional friends, I was told that a crucial incision would hav leen best, as the approved practice in obstructed menses, etc.; but from this I dissent. In primiparæ, where the os is like "a minnte cicatrix", "a small crowquill", "a slight indentation", or is " impervious, hard, and circular", the crucial incision may be the very best; but where the known recently existing state of parts was that of ample development after repented child-bearing, and where, therefore, the new formation must extend, lengthwise, from side to side, and be comparatively narrow from back to front, such incision was neither required nor applicable. Bleeding, large or small, was never thought of. It startles one to read of the Cxsarean operation having been performed "in a case of this kind"; and as for destruction of the child in Mr. Hatton's case, this was resorted to on other grounds than the occlusion, and which were deemed sufficient to demand so serious an expedient.

\section{CASE OF CUT-THROAT: RECOVERY.}

By Wimliaji Timcralu, Esq., Bedford.

[. Fival bejore the South Midland Branch, September 29th, 185\%.]

Os September th, 185\%, G., aged about 3r, a sub-contractor on the Leicester and Hitchin Railway, attempted selfdestruction aboit $4 \cdot 30$ p.r., by cutting his throat with a razor. He had been in a desponding state of mind for some time previous to the injury, and had suffered from severe diarrhœa for four lays.

When I arrived at the honse, about half an hour after the occurrence, I found him upstairs lying on his back, having been placed in that position ly two of his neighlibours, who attended immediately upon the alarm being given by his wife. There was a very large quantity of blood unon the fioor, and upon examining the wousd, I found that an incision, about four inches in length, had been made across the os hyoides, which bone had a groove across the whole of the front surface produced by the razur; a second incision had evidently been made a little higher up, which was six inches in length, and extended from about half an inch from the left angle of the jaw to the right angle of the jaw. The muscles were all divided above the larynx, and the cesophagus was cut through the whole extent, except a small portion at the posterior part. The internal edge of the wound on the right side appeared to be more extensive than the external, as though the point of the razor had been depressed when it arrived at that part, and the muscles in that situation were sery much jaggel. Upon removing a quantity of coagulated blood from the throat, the large vessels on the left side were found to have just escaped the instrument, but both external and internal carotids on the right side were divided. When the clotted blood was removed from the wound, a gush of blood took place from the external carotid, which was immediately secured, and, while the ligature was being applied to it, a very considerable jet of blood, evidently from the internal carotid, took place; I immediately seized with a pair of forceps a mass of muscle in the direction of the jet, which arrested the hæmorrhage, and as soon as the external was secured, I proceeded to search for the wounded internal, but from the jagged state of the muscles, the great retraction of the vessel, and the hiemorrhage having ceased, it could not be found. The upper end of the external carotid was secured as well as the lower. Another artery, probably the lingual or anterior facial, was secured, also a vein which bled freely, and was supposed to be the sublingual. Mr. Harris of Springfield, who was passing by at the time, was kind enough to render me valuable assistance.

The man oppeared fast sinking, and about an hour after the injury the pulse at the wrist was barely perceptible; it gradually became weaker, until quite imperceptible, and remained so for at least four hours, during which time the only way I could tell that a spark of life remained, was by placing a candle near the wound and examining the epiglottis, which merely quivered, but did not half close the glottis. So convinced was I that the man was fast sinking, that I spoke to the chief constable as to the time the inquest would be likely to be held the following day. Reaction very gradually returned, and about eleven o'clock he was carefully removed from the floor (where he had remained from the time of the injury), and placed in bed. He vomited three or four times during the night, when a dark grumous fluid gushed through the wound, a very small quantity upon one occasion coming out of the mouth.

Sertember 5th. At 7 A.Mr. his pulse had much improved, he became perfectly sensible, and made signs for his daughter to come to him. No hæmorrhage had taken place during the night, but a considerable quantity of saliva and mucus tinged with blood continued to escape from the wound. During the day, he was enabled to write on a slate anything he wished to communicate; and in the evening, the tube of a stomach-pump was introduced through the mouth into the stomach, and about a pint and a half of new milk was injected by means of an India-rubber hydrocele bottle.

From September 5th to the 10th, he continued to sleep well at night, and about a pint and a half of strong beef tea was thrown into his stomach night and morning. On the morning of the 10th, Mr. Couchman and myself closed the wound about two-thirds in extent by means of several sutures, the patient having been kept constantly from the time of the injury on his left side with the head well bent forward on the chest; about an inch and a half of the wound on the left side was left open to allow the mucus and saliva to escape. In the evening, an aperient was given with his food, his bowels not having been opened since the injury.

September 11th. He had a restless night, and complained of much pain in the wound since the sutures were applied. There was a slight erysipelatous blush about the edges of the wound. Cold water dressing was applied; the bowels were not yet relieved; pulse 84. Up to this time, when he tried to talk, the sound was a hoarse lind of whisper, and only a very few words could be understood.

September 12th. He had a better night; pulse the same as yesterdav. The bowels were slightly moved; the aperient was repeated. During the night, the patient sneezed and tore out several of the sutures, and the wound being disposed to gape, a broad band of strapping was applied round the throat just below the lower edge of the wound. He said he felt better the inflammation about the wound was less; and the discharge looked healthy.

From this time he progressed favourably; and about three weeks after the injury, he was able to swallow fluids with care, pretty well; and at the end of about two months, the wound was perfectly healed. Mastication, deglutition, and speech, were impaired for four or five months after the injury, but gradually improved; and eighteen months afterwards, the only perceptible inconvenience was a rather guttural sound of the voice.

\section{USE OF COFFEE IN THE TREATMENT OF STRANGULATED HERNIA.}

By Joseph B. SAmint, M.D., Malta.

$\mathrm{H}_{\Delta \mathrm{viNG}}$ lately perused an Italian medical journal, I was struck with the simplicity of a remedy proposed for cases of strangulated hernia; the efficacy of which I have since had occasion to prove. Not having observed any mention of it amongst the several remarks on this subject in our JOURNAL, I think it might not be unacceptable to draw attention to a method of cure at once so simple and easily obtained. The case was as follows. A coloured man, aged about 55, very robust, cook in a merchant vessel, had been in the habit of wearing a truss for an incipient inguinal hernia, but had left it off for some time. On the evening of October 7 th, he, having spent some hours on shore, returned on board somewhat intoxicated, and commenced wrestling with some of the men, when, on a sudden, he felt so severe a pain in the right inguinal region, as to lead him to suppose he had received a kick, but which, from subsequent information, I have reason to conclude was not the case, but simply the hernia descending into the scrotum. He was put to bed, and in some hours afterwards symptoms of strangulation appeared. I did not see him till the following morning between seven and eight o'clock. Having placed him in a convenient position, I tried the taxis, but the patient could not suffer my touching him. I then determined to try strong infusion of coffee (one ounce to each cup), when, to my surprise, after drinking the first cup, the patient's face appeared less anxious, and I was enabled to reduce the hernia with little trouble. This was a result hardly to be anticipated, as the desired effect does not usually take place before administering half a dozen cups, allowing a quarter of an hour to intervene between each. This remedy is frequently used in Habana with success, and has been often tried with equal success by many practitioners; at times in combination with the bath, belladonna ointment over the tumour, etc. 